\title{
The effect of molecular weight and hydrolysis degree of poly(vinyl alcohol)(PVA) on the thermal and mechanical properties of poly(lactic acid)/PVA blends
}

\author{
Iván Restrepo ${ }^{1,2}$, Carlos Medina ${ }^{3}$, Viviana Meruane ${ }^{4}$, Ali Akbari-Fakhrabadi ${ }^{4}$, Paulo Flores ${ }^{3 *}$ \\ and Saddys Rodríguez-Llamazares ${ }^{5}$ \\ 'Departmento de Ingeniería de Materiales, Universidad de Concepción, Concepción, Chile \\ ${ }^{2}$ Unidad de Desarrollo Tecnológico, Universidad de Concepción, Coronel, Chile \\ ${ }^{3}$ Departamento de Ingeniería Mecánica, Universidad de Concepción, Concepción, Chile \\ ${ }^{4}$ Laboratorio de Materiales Avanzados, Departamento de Ingeniería Mecánica, Universidad de Chile, \\ Santiago, Chile \\ ${ }^{5}$ Centro de Investigación de Polímeros Avanzados, Concepción, Chile \\ *pfloresv@udec.cl
}

\begin{abstract}
The effect of molecular weights and hydrolysis degrees (HD) of polyvinyl alcohol (PVA) on thermal and mechanical properties and crystallinity of polylactic acid (PLA)/PVA blends was investigated. Blends were prepared by the melt blending method using PLA/PVA ratios: 80/20, 90/10 and 97/3 wt. \%. A single glass transition temperatures was observed for all PLA/PVA blends, suggesting the formation of binary compatible blends at concentration range studied. Thermogravimetric analysis results showed a better thermal stability for PLA/PVA blends containing PVA of higher Mw and HD. According to mechanical properties, low quantities of PVA (3 wt. \%) do not affect the tensile strength of blends (irrespective of Mw and HD). However, as the PVA content increases, tensile strength tends to lower values, especially for blends with 20 wt. $\%$ of PVA, with $98 \%$ of HD.
\end{abstract}

Keywords: material testing, melt blending, polylactic acid, polyvinyl alcohol, polymer blend.

\section{Introduction}

Polylactic acid (PLA) is a linear aliphatic polyester obtained from renewable sources such as starch and sugar. It is one of the most widely used bioplastics due to its optical, mechanical and barrier properties, and good processability by conventional transformation techniques of thermoplastics ${ }^{[1]}$. The worldwide production capacity of PLA in 2021 is estimated around 297.000 tons, $40 \%$ more than that produced in $2016^{[2]}$. PLA is classified by the American food and drug administration as generally recognized as safe and hence it is very common in the food packaging industry. Its barrier, thermal and mechanical properties are in fact similar to those of synthetic polymers such as polystyrene ${ }^{[3-6]}$.

PLA can be biodegraded under compost conditions; it takes up to a year to degrade in real and simulated soil burial conditions. This slow degradation compared to other polymers such as for example poly (hydroxy alkanoates), is due to the fact that PLA must be hydrolyzed before microorganisms can use it as a source of nutrients ${ }^{[7,8]}$. Adding small quantities of compatible hydrophilic polymers such as PVA, which is biodegradable, hydrophilic and flexible ${ }^{[9]}$ is a way to enhance the biodegradability of PLA. For example, it has been reported that polyvinyl alcohol (PVA) has the ability to accelerate the degradation of PLA, by increasing the hydrophilicity of the blend and breaking the crystallinity of PLA ${ }^{[10]}$. Furthermore, the hydroxyl groups in PVA readily form hydrogen bonds with the ester groups of PLA, which favors the compatibility of their blends. Yeh et al., (2008) $)^{[11]}$ found that a compatible blend PLA: PVA (80: 20 wt. \%: wt. \%) prepared by melt blending method using PLA Mw $=37 \mathrm{~kg} / \mathrm{mol}$ and PVA with $\mathrm{HD}=97-98.5 \%$ and $\mathrm{Mw}=75 \mathrm{~kg} / \mathrm{mol}$. Similar results were reported by Shuai et al., 2001 ${ }^{[12]}$ for blends PLA/PVA 10 to 90 wt. $\%$ of PVA with polymerization degree of 2000 and $\mathrm{HD}=99 \%$. They report the formation of interpolymer hydrogen bonds in the amorphous region of PLA/PVA blends (PVA content higher than $50 \mathrm{wt}$. \%), which contributes to compatibility of these blends. However, PVA and PLA crystallized as isolated phases, for that tensile strength and elongation at break first declines for PVA content from 0 to $50 \mathrm{wt}$. $\%$ and then increases with increasing when the PVA content.

Several authors have reported the effect of PVA content with different $\mathrm{HD}$ and $\mathrm{Mw}$ on mechanical properties of PLA/PVA blends. For example, Lipsa et al. (2008) $)^{[13]}$ prepared films by these blends using PVA with $\mathrm{HD}=98 \%$ and $\mathrm{Mw}=18 \mathrm{~kg} / \mathrm{mol}$. They found that the blends are partially compatible for PVA content from 70 to $90 \mathrm{wt}$ \%, and slight reduction of mechanical properties, such as lower tensile strength were observed in blends.

Tsuji and Muramatsu (2001) ${ }^{[14]}$ found that the Young's modulus, tensile strength and percent elongation at break 
of the blends increase with increasing PVA content from 50 to 90 wt. $\%(\mathrm{HD}=99.5 \%)$. Hoai N. et al. $(2014)^{[15]}$ prepared nanofibrillary structures from PLA/PVA blends, varying content of PVA from 0 to $100 \mathrm{wt}$. \%. They found that increasing the amount of PVA results the thermal degradation of blends more stable.

However, a systematic study that show the influence of content, molecular weight and hydrolysis degree of PVA on compatibility, and therefore on the thermal and mechanical properties and crystallinity of PLA has not found. In this work, PLA/PVA blends prepared by the melt blending method was studied.

\section{Materials and Methods}

\subsection{Materials}

The commercial PLA grade 3251D, Mw of $55.4 \mathrm{~kg} / \mathrm{mol}$ and isomer D lactic acid content of $1.2 \%^{[16]}$ was purchased from Nature Works ${ }^{\circledR}$, United States. Four different types of PVA with different hydrolysis degree and molecular weight were provided by Sigma Aldrich ${ }^{\circledR}$. The main specifications of PVA are summarized in Table 1. The pure PLA processed under similar conditions was studied as reference material.

\subsection{Processing}

The PLA/PVA blends, ratios of $80 / 20,90 / 10$ and $97 / 3$ wt. \% for each type of PVA (Table 1), were prepared via melt blending in a Brabender mixer (Plastograph ${ }^{\circledR}$ EC plus, Mixer 50EHT32, Germany) at $60 \mathrm{rpm}$ for $8 \mathrm{~min}$. The temperature was set at $190{ }^{\circ} \mathrm{C}$. The PLA was previously dried at $40{ }^{\circ} \mathrm{C}$ overnight in a vacuum oven. After blending, the samples were pressure-molded at 30 bar and $10 \mathrm{~min}$ in order to obtain plates for XRD and impulse excitation technique (IET) tests. The temperature was set between 170 and $210^{\circ} \mathrm{C}$, depending on the type of PVA used in the preparation of the sample.

\subsection{Blend characterization}

\subsubsection{DSC}

The thermal properties of PLA/PVA blends were evaluated using a differential scanning calorimetry (DSC) analyzer (Netzsch DSC 204 F1 Phoenix), Germany. DSC curves were scanned at $10^{\circ} \mathrm{C} / \mathrm{min}$ under nitrogen atmosphere (20 $\mathrm{mL} / \mathrm{min})$. The DSC scans were performed from room temperature to $250{ }^{\circ} \mathrm{C}$. Then, the samples were cooled to $25^{\circ} \mathrm{C}$ and a second heating scans were made up to $250^{\circ} \mathrm{C}$. Glass transition temperature $(\mathrm{Tg})$, cold crystallization

Table 1. Nomenclature of blends.

\begin{tabular}{|c|c|c|c|c|c|}
\hline \multirow{2}{*}{$\begin{array}{l}\text { PVA } \\
\text { Code }\end{array}$} & \multicolumn{2}{|l|}{ PVA } & \multicolumn{3}{|c|}{$\begin{array}{l}\text { Sample code for } \\
\text { PLA/PVA blends }\end{array}$} \\
\hline & $\begin{array}{c}\text { Range of } \\
\text { Mw (g/mol) }\end{array}$ & $\begin{array}{l}\text { HD } \\
(\%)\end{array}$ & $\begin{array}{l}80 / 20 \\
\text { wt. } \%\end{array}$ & $\begin{array}{l}90 / 10 \\
\text { wt. } \%\end{array}$ & $\begin{array}{r}97 / 3 \\
\text { wt. } \%\end{array}$ \\
\hline 1PVA & $13000-23000$ & $87-89$ & $\begin{array}{l}\text { 1PVA } \\
80 / 20\end{array}$ & $\begin{array}{l}\text { 1PVA } \\
90 / 10\end{array}$ & $\begin{array}{c}\text { 1PVA } \\
97 / 3\end{array}$ \\
\hline 2PVA & $13000-23000$ & 98 & $\begin{array}{l}2 \mathrm{PVA} \\
80 / 20\end{array}$ & $\begin{array}{l}2 \mathrm{PVA} \\
90 / 10\end{array}$ & $\begin{array}{c}2 \mathrm{PVA} \\
97 / 3\end{array}$ \\
\hline 3PVA & $31000-50000$ & $87-89$ & $\begin{array}{l}3 \mathrm{PVA} \\
80 / 20\end{array}$ & $\begin{array}{l}3 \mathrm{PVA} \\
90 / 10\end{array}$ & $\begin{array}{c}3 \mathrm{PVA} \\
97 / 3\end{array}$ \\
\hline 4PVA & $31000-50000$ & 98 & $\begin{array}{l}4 \mathrm{PVA} \\
80 / 20\end{array}$ & $\begin{array}{l}4 \mathrm{PVA} \\
90 / 10\end{array}$ & $\begin{array}{c}\text { 4PVA } \\
97 / 3\end{array}$ \\
\hline
\end{tabular}

temperature (Tcc), cold crystallization enthalpy $(\Delta \mathrm{Hcc})$, melting temperature $(\mathrm{Tm})$, melting enthalpy $(\Delta \mathrm{Hm})$, and degree of crystallinity $\left(X_{C}\right)$ were determined from the second heating scans. $X_{C}$ of PLA in the blends was calculated by the Equation (1):

$$
X c=\left(\Delta H_{m} /\left(\Delta H^{\circ}{ }_{m} W\right)\right) 100 \%
$$

where $\Delta \mathrm{H}_{M}$ is the melting enthalpy of the blends, $W$ is the weight fraction of PLA and $\Delta \mathrm{H}^{\circ}{ }_{M}$ is the melting enthalpy of $100 \%$ crystalline PLA $(93 \mathrm{~J} / \mathrm{g})^{[17,18]}$.

\subsubsection{TGA}

Thermal stability of pure PLA, PVA's and their blends was evaluated using a thermogravimetric analyzer Netzsch TGA 209 F3 (Tarsus, Selb, Germany). TGA scans were carried out at $10{ }^{\circ} \mathrm{C} / \mathrm{min}$ under nitrogen atmosphere $(20 \mathrm{ml} / \mathrm{min})$, from 35 to $600{ }^{\circ} \mathrm{C}$.

The following parameters were reported: $(i)$ temperature at maximum decomposition rate for each step of decomposition $\left(\mathrm{T}_{\max }\right)$, (ii) weight loss associated with $\mathrm{T}_{\max }\left(\mathrm{WL} \mathrm{T}_{\max }\right.$ ), (iii) the onset temperature $\left(\mathrm{T}_{\text {onset }}\right)$ corresponding to each decomposition step and (iv) the temperature corresponding to $5 \%$ weight loss $\left(\mathrm{T}_{5 \%}\right)$.

\subsubsection{XRD}

The XRD measurements were recorded on a Bruker diffractometer Endeavor model D4/MAX-B (United States) operated at $40 \mathrm{kV}, 20 \mathrm{~mA}$, at room temperature, using a $\mathrm{CuK \alpha}$ source and $\lambda=1.5405 \AA$. The diffraction spectra were taken in the range $3^{\circ}<2 \theta<45^{\circ}$ at $0.02^{\circ}$ steps and a scanning rate of $1 \% \mathrm{~min}$. The pure PLA and PLA/PVA blends were previously annealed for $20 \mathrm{~min}$ at $120^{\circ} \mathrm{C}$ under vacuum conditions.

\subsubsection{Tensile test}

The mechanical properties of PLA/PVA blends were evaluated using tensile test performed on a Karg Industrietechnik machine (Germany) according to ASTM D638 standards. Samples type V were fabricated using a mini injection equipment type Haake Minijet II, and injection conditions were 350 bar of pressure and injection temperature of $180^{\circ} \mathrm{C}$. Prior testing, specimens were conditioned under $25^{\circ} \mathrm{C}$ and $50 \%$ relative humidity (R.H) for 7 days. The crosshead speed was set at $10 \mathrm{~mm} / \mathrm{min}$. The Young's modulus, strength and elongation percentage at break were obtained from the stress-strain curves. At least 5 individual measurements were carried out for each formulation and mean values and standard deviations were reported. Collected data were evaluated with a one-way analysis of variance at the $95 \%$ confidence level.

For comparison purpose, elastic modulus of PLA/PVA blends were evaluated by Impulse excitation technique (IET). The rectangular samples were suspended by soft and tiny tape sticks to simulate a "free-free" boundary condition and were excited by an impact hammer. The samples have an aspect ratio of $a / b=1.5$, where $a, b$ are the plate's length and width dimensions, respectively. The vibration of the samples is captured by a microphone which was connected to a data acquisition system. A signal processing software computed the frequency content of the measured signals from which the experimental resonant frequencies were identified. Once the experimental resonant frequencies 
were identified, the elastic modulus was computed using the relationships presented in Equation $(2)^{[19]}$ :

$$
\omega=\frac{21.603 h}{a^{2}} \sqrt{\frac{E}{12 \rho\left(1-v^{2}\right)}}
$$

where $v=0.4$ is Poisson's ratio, $\rho$ is the density, $E$ is the elastic modulus and $h=0.85$ and $a=20$ are plate's dimensions (thickness and length respectively, in millimetres). The variable $\omega$ corresponds to the second resonant frequency of the plate, which was easier to be excited and measured.

\subsubsection{SEM}

The morphology of cryogenic-fractured cross-sections of PLA/PVA blends was analyzed by scanning electron microscopy (JEOL JSM 6380 LV, Tokyo-Japan), operated at 20 and $5 \mathrm{kV}$. The samples were fractured under liquid nitrogen and sputtered with a gold coating of ca. $50 \mathrm{~nm}$. The magnifications were 100x and 500x

\section{Results and Discussion}

\subsection{DSC Analysis}

DSC thermograms of PLA, PVA's and PLA/PVA blends are shown in Figure 1. The thermograms for pure PLA and PLA/PVA blends display successive peaks corresponding to the glass transition, cold crystallization and melting. The Tg, Tcc and Tm are resumed in Table 2 . The only one peak of Tg is observed for PLA/PVA blends, which is ranged from 42 to $55^{\circ} \mathrm{C}$, intermediate between the $\mathrm{Tg}$ values of pure PLA and PVA. This behavior is characteristic of compatible blends. Shuai et al., $2001^{[12]}$ found by ${ }^{13} \mathrm{C}$ solid-state nuclear magnetic resonance spectroscopy, the presence of hydrogen bonds between hydroxyl groups of PVA and carbonyl groups of PLA in the amorphous region of blends with
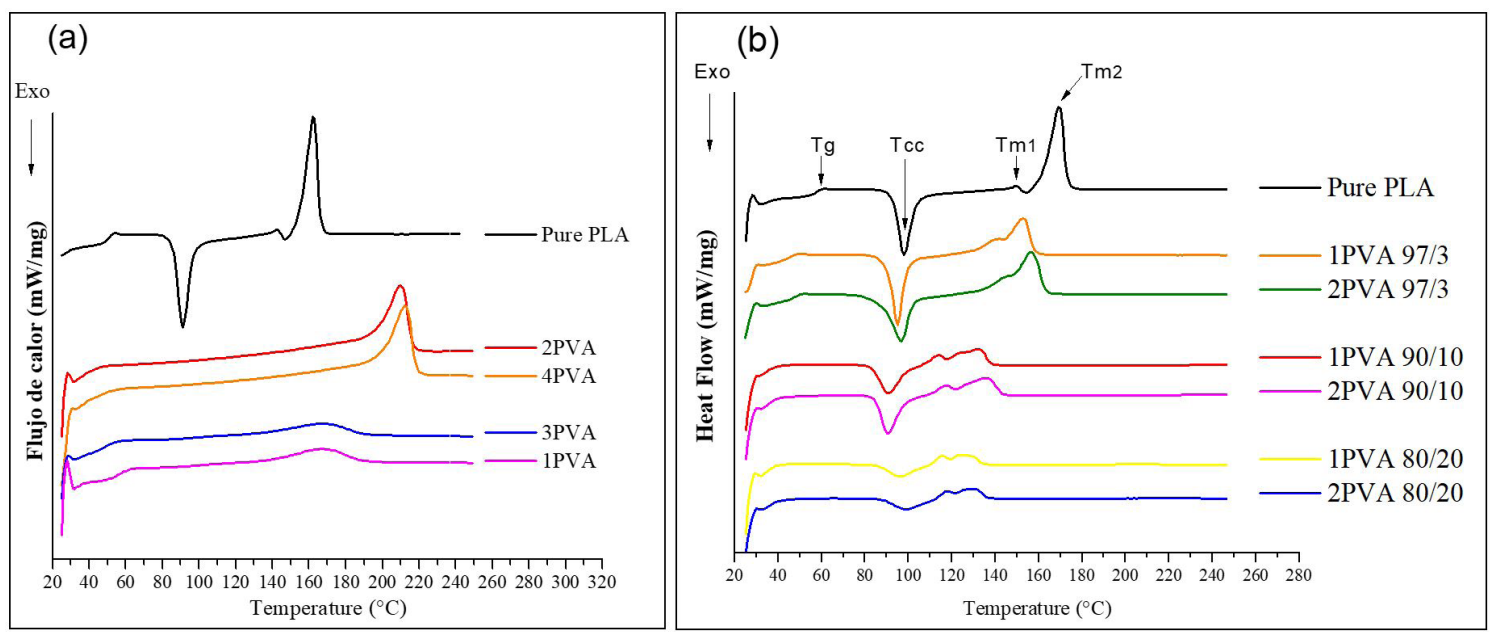

Figure 1. Second heating run DSC thermograms for: (a) Pure PLA and PVA's; (b) PLA/PVA blends.

Table 2. Thermal characteristics of pure PLA, PVA's and PLA/PVA blends.

\begin{tabular}{|c|c|c|c|c|c|c|c|}
\hline Sample code & $\operatorname{Tg}\left({ }^{\circ} \mathrm{C}\right)$ & $\operatorname{Tcc}\left({ }^{\circ} \mathrm{C}\right)$ & $\operatorname{Tm} 1\left({ }^{\circ} \mathrm{C}\right)$ & $\operatorname{Tm} 2\left({ }^{\circ} \mathrm{C}\right)$ & $\Delta H_{c c}\left(J^{\prime} g^{-1}\right)$ & $\Delta \mathrm{Hm}\left({\mathrm{J} . g^{-1}}^{-1}\right)$ & Xc (\%) \\
\hline Pure PLA & 61 & 98 & 150 & 169 & 38 & 54 & 58 \\
\hline 1PVA & 37 & - & 167 & - & - & 20 & - \\
\hline 1PVA 80/20 & 42 & 96 & 116 & 124 & 13 & 14 & 19 \\
\hline 1PVA 90/10 & 43 & 91 & 114 & 133 & 24 & 22 & 26 \\
\hline 1PVA 97/3 & 50 & 95 & 142 & 153 & 39 & 41 & 45 \\
\hline 2PVA & 40 & $\ldots$ & 210 & $\ldots$ & - & 66 & 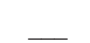 \\
\hline 2PVA 80/20 & 44 & 99 & 118 & 130 & 13 & 14 & 19 \\
\hline 2PVA 90/10 & 42 & 91 & 118 & 136 & 28 & 25 & 30 \\
\hline 2PVA 97/3 & 53 & 97 & 143 & 157 & 41 & 49 & 54 \\
\hline 3PVA & 44 & - & 167 & - & - & 21 & $\ldots$ \\
\hline 3PVA 80/20 & 55 & 89 & 111 & $\overline{132}$ & $\overline{16}$ & 15 & 20 \\
\hline 3PVA 90/10 & 43 & 92 & 121 & 138 & 27 & 23 & 27 \\
\hline 3PVA 97/3 & 50 & 94 & 143 & 157 & 45 & 52 & 57 \\
\hline 4PVA & 42 & - & 212 & - & - & 61 & \\
\hline 4PVA $80 / 20$ & 51 & 91 & 112 & $\overline{130}$ & $\overline{14}$ & 16 & 22 \\
\hline 4PVA 90/10 & 42 & 88 & 117 & 136 & 32 & 27 & 32 \\
\hline 4PVA 97/3 & 54 & 94 & 149 & 159 & 40 & 47 & 53 \\
\hline
\end{tabular}


PVA content of $30 \mathrm{wt} . \%$. A single Tg of PLA/PVA blends with PVA content lower than $20 \mathrm{wt} . \%$ is attributed to this kind of interpolymer interaction. Tg peak is shifted to lower temperatures with increasing PVA content in the blends.

The blends and pure PLA exhibited two endothermic peaks of melting characteristic of the formation of two PLA crystal structures during its cold crystallization, known as $\alpha$ and $\beta$ forms with melting temperatures $\operatorname{Tm} 2$ and $\mathrm{Tm} 1$ respectively. The melting temperature of the $\alpha$-form is higher because of the better quality and higher size of its crystals ${ }^{[20,21]}$. The melting temperatures of the blends are also shifted toward lower temperatures, with increasing the PVA content irrespective of Mw and HD.

The $X c$ values for PLA in blends decrease, especially when $20 \mathrm{wt} . \%$ of PVA was added. Thus, the crystallization of PLA in presence of PVA is affected due to the formation of imperfect crystals in PLA by considering that the presence of the PVA can cause a dilution of the PLA nuclei, combined with the possible interference between the chains of PLA and PVA due to partial compatibility between them. Opposite results were obtained by Yeh et al., (2008) ${ }^{[11]}$ who found that highest PLA crystallinity, appears in PLA/PVA blends containing 20 wt. \% of PVA(MW: 75KDa, HD: 98\%), attributed to the interactions between PLA and PVA that promote the crystallization. However, Tsuji and Muramatsu (2001) $)^{[14]}$ report a zero $X c$ value of PLA for all PLA/PVA blends (ratio 90:10 to 50:50 wt. \%) indicating that PLA is amorphous in the blend. On the other hand, Shuai et al., (2001) ${ }^{[12]}$ reported a decrease in $X c$ values of PLA when PVA is added in contents more than $70 \mathrm{wt} . \%$, result of some depression of the PLA crystallinity upon blending with a large amount of PVA.

Variations in values of Tcc, Tm, and $X c$ in PLA/PVA blends are usually attributed to interactions between the components. In general, the decrease in PLA crystallinity is related to the partially compatible nature of the blends ${ }^{[11,22]}$.

\subsection{TGA Analysis}

Thermal stability of pure PLA, PVA's and PLA/PVA blends was evaluated by TGA analysis. Table 3 summarizes the thermal parameters. The TGA curve for pure PLA showed one-step degradation with a weight loss of $99 \%$, associated with the loss of ester groups by unzipping depolymerization ${ }^{[23,24]}$. $\mathrm{T}_{\max }$ for pure PLA was $364^{\circ} \mathrm{C}$. In contrast, pure PVA's displayed three degradation steps. The first one, between 31 and $188{ }^{\circ} \mathrm{C}$ and a weight loss below $5 \mathrm{wt}$. \%, is associated with the loss of absorbed moisture. The second step, between 190 and $388^{\circ} \mathrm{C}$ and a weight loss ranged from 65 to $77 \%$, is related to the loss of low molecular weight substances, such as residual acetate groups, non-conjugated polyenes, acetic acid and $\mathrm{H}_{2} \mathrm{O}$. The third step, between 351 and $426^{\circ} \mathrm{C}$, is associated to the breakdown of polymer backbone ${ }^{[25]}$. The main product of thermal degradation of PVA is water, which is formed by the elimination of hydroxyl side-groups ${ }^{[26]}$.

For the same Mw, PVA with higher HD (98\%) showed the lowest values of $\mathrm{T}_{\text {max- } 1}$ in the second step of degradation with values around $260^{\circ} \mathrm{C}$ and weight loss associated with this $\mathrm{T}_{\text {max- }-1}$ was $69-71 \%$ (see Table 3 ). Therefore, PVA with HD of $87-89 \%$, present better thermal stability. Acetate groups present in PVA with lower HD, confer higher thermal decomposition temperatures to PVA, favoring its thermal stability ${ }^{[27]}$.

Two degradation steps were observed for PLA/PVA blends, (see Figure 2) suggesting that thermal decomposition of PVA and PLA happens as a combined process ${ }^{[25]}$. The first step of decomposition was between 188 and $386^{\circ} \mathrm{C}$ with a weight loss of 75-98 wt.\%. The second one was between 381 and $507{ }^{\circ} \mathrm{C}$ with a weight loss $0.2-2.2$ wt. \%. With increasing PVA content in the blends, the main degradation step is shifted significantly to lower temperatures. Water absorbed by PVA, could be favoring hydrolytic degradation of PLA.

Table 3. TGA and DTG parameters for pure PLA, PVA and PLA/PVA blends.

\begin{tabular}{|c|c|c|c|c|c|c|c|}
\hline \multirow{2}{*}{ Sample code } & \multirow{2}{*}{$\begin{array}{c}\text { TGA } \\
\mathbf{T}_{5 \%}\end{array}$} & \multicolumn{6}{|c|}{ DTG } \\
\hline & & $\mathrm{T}_{\text {on set- } 1}\left({ }^{\circ} \mathrm{C}\right)$ & $\mathrm{T}_{\max -1}\left({ }^{\circ} \mathrm{C}\right)$ & WL-1 (\%) & $\mathrm{T}_{\text {On set-2 }}\left({ }^{\circ} \mathrm{C}\right)$ & $\mathrm{T}_{\text {max }-2}\left({ }^{\circ} \mathrm{C}\right)$ & WL-2 (\%) \\
\hline Pure PLA & 334 & 284 & 364 & 99 & & & \\
\hline 1PVA & 241 & 216 & 306 & 77 & 391 & 426 & 12 \\
\hline 1PVA 80/20 & 268 & 191 & 301 & 90 & 381 & 425 & 7 \\
\hline 1PVA 90/10 & 280 & 232 & 312 & 92 & 392 & 427 & 5 \\
\hline 1PVA 97/3 & 301 & 256 & 353 & 97 & 411 & 420 & 1 \\
\hline 2PVA & 186 & 216 & 261 & 69 & 351 & 421 & 15 \\
\hline 2PVA 80/20 & 272 & 188 & 305 & 93 & 383 & 428 & 4 \\
\hline 2PVA 90/10 & 286 & 231 & 330 & 95 & 406 & 419 & 2 \\
\hline 2PVA 97/3 & 301 & 251 & 348 & 97 & 411 & 421 & 1 \\
\hline 3PVA & 261 & 221 & 314 & 75 & 391 & 426 & 16 \\
\hline 3PVA 80/20 & 275 & 218 & 305 & 88 & 388 & 432 & 7 \\
\hline 3PVA 90/10 & 285 & 225 & 322 & 93 & 395 & 422 & 3 \\
\hline 3PVA 97/3 & 301 & 241 & 345 & 97 & 406 & 427 & 1 \\
\hline 4PVA & 215 & 206 & 260 & 71 & 351 & 416 & 14 \\
\hline 4PVA 80/20 & 270 & 220 & 380 & 87 & 390 & 435 & 4 \\
\hline 4PVA 90/10 & 288 & 240 & 331 & 94 & 393 & 427 & 3 \\
\hline 4PVA 97/3 & 311 & 261 & 356 & 98 & 421 & 431 & 1 \\
\hline
\end{tabular}


The Tmax-1 shifts to higher values for those blends with PVA's of higher Mw and higher HD. With increasing Mw of PVA, the entanglement along the chains of PLA and PVA is favored. These results are in agreement with some literature reports $^{[28-30]}$ for higher Mw of PVA, which favors intramolecular entanglement between PVA and PLA, primarily by virtue of esterification of PVA hydroxylic groups and PLA carboxylic groups, improving the thermal stability of PVA in the blend.

\subsection{XRD analysis}

The XRD diffraction patterns for pure PLA, PVA and selected PLA/PVA blends are shown in Figure 3. The results are shown only for two types of blends, considering that the diffraction patterns for all PLA/PVA blends and pure PLA were very similar.

The most intense peaks for PVA's appeared around $2 \theta=19.3^{\circ}, 20^{\circ}$ and $22.7^{\circ}$, related to reflections of planes $1 \overline{01}, 101$, and 200 , respectively, associated with a monoclinic unit cell[14]. Assender and Windle, $1998^{[31]}$ reported that
PVA chains are lying along the b-axis of the unit cell. Two characteristic peaks of pseudo orthorhombic $\alpha$-phase crystallites structure (Space group P $3_{2}$ ) were observed for pure PLA, around 16.5 and $18.8^{\circ}(2 \theta)$, corresponding to the reflection of $110 / 200$ and 203 planes with two chains in a helical conformation ${ }^{[11,32,33]}$.

The absence of characteristic PVA peaks in blends is attributed to the absence of PVA crystallization in the presence of PLA suggesting that PVA molecules was trapped in an amorphous state in the PLA phase and/or PLA molecules reduce the nucleus density of PVA crystallites ${ }^{[14]}$. In this context, Shuai et al. (2001) ${ }^{[12]}$ reported the presence of two isolated crystalline phases (called co-crystalline phase) coexisting in PLA/PVA blends (ratio 1:1), that have the same crystal structure without inter-polymer interactions between them. Furthermore, with the addition of PVA in PLA, all of the blends show no shift in characteristic diffraction peaks of PLA, implying that, there is no significant effect of PVA on the crystal structure of PLA ${ }^{[11]}$.

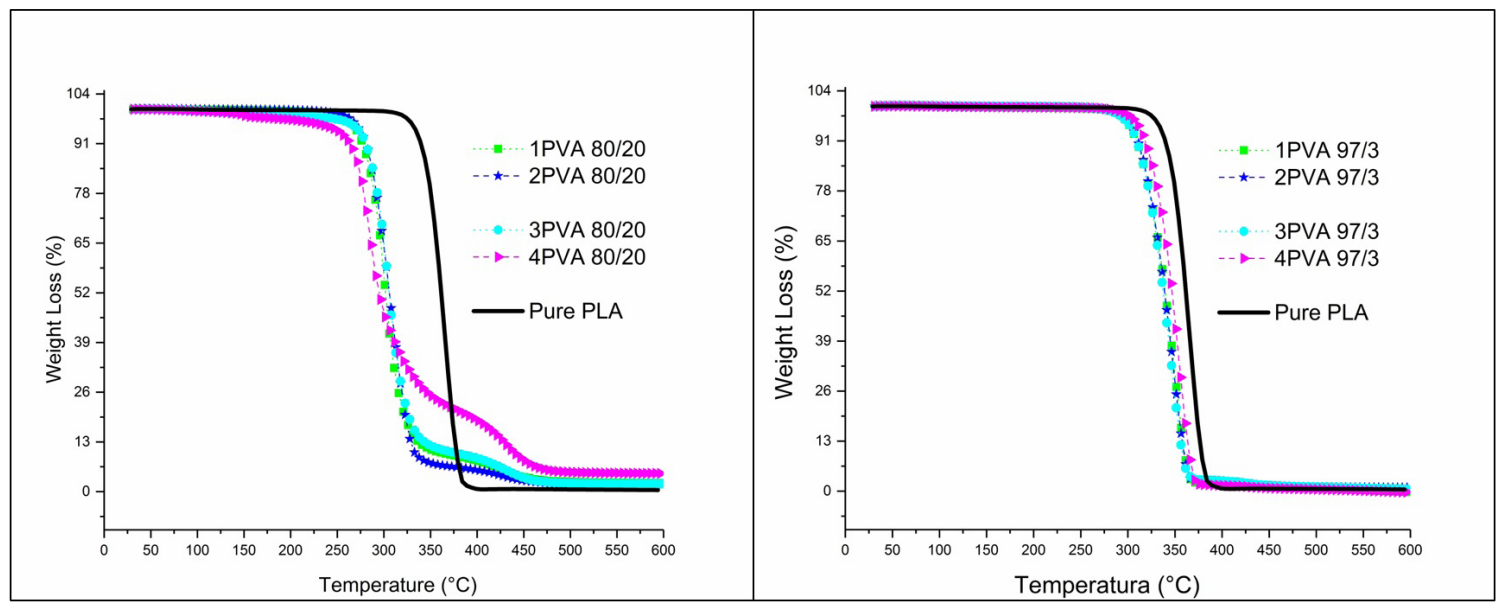

Figure 2. TGA diagrams for (a) Pure PLA, PVA's; (b) blends PLA/PVA: 80/20 wt. \% blends; (c) blends PLA/PVA: 97/3 wt. \%.
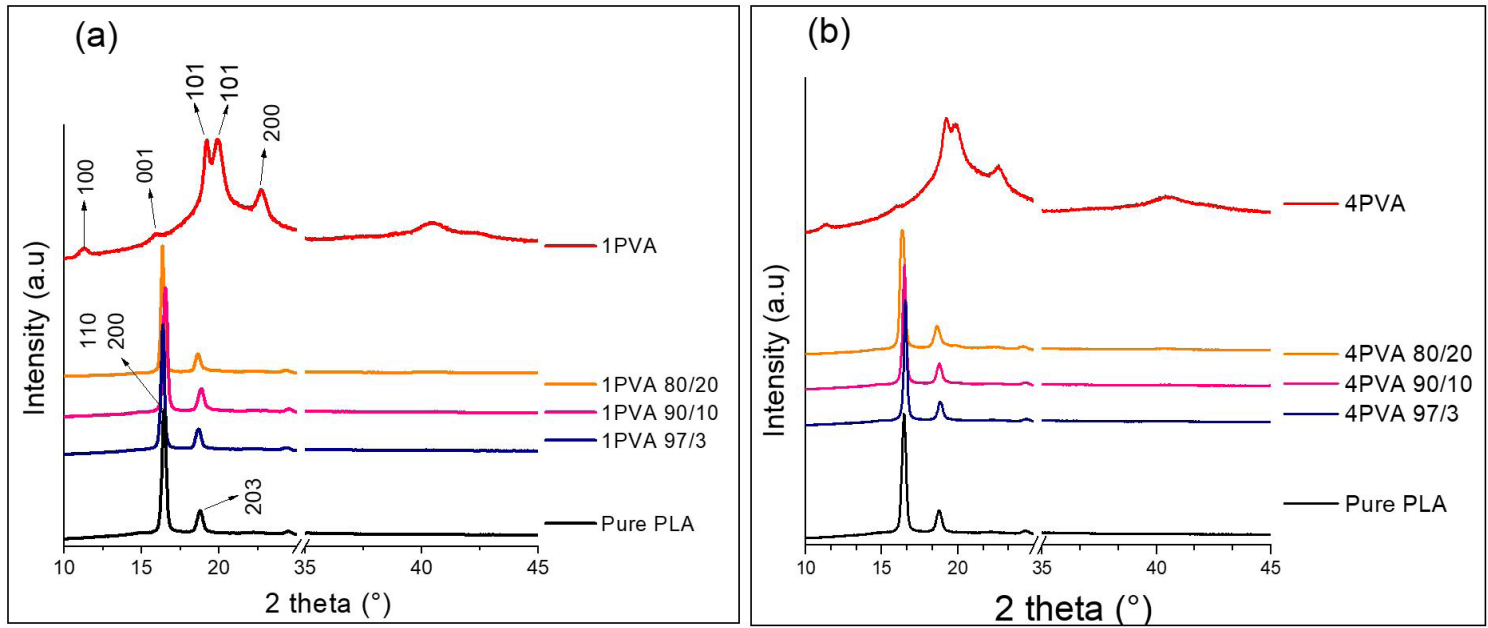

Figure 3. Diffractions patterns for: (a) PLA/1PVA blends and (b) PLA/4PVA blends. 


\subsection{Mechanical analysis}

Tensile strength of pure PLA and PLA/PVA blends are shown in Figure 4. Compared with pure PLA, the tensile strength of blends containing $3 \mathrm{wt}$ \% of PVA, is very similar (irrespective of Mw and HD). However, as the PVA content increases, tensile strength tends to lower values, especially for blends with 20 wt. $\%$ of PVA, with $98 \%$ of HD.

Influence of $\mathrm{Mw}$ is observed for blends with $10 \mathrm{wt} . \%$ of PVA. Thereby, blends containing PVA with higher Mw showed higher values in the tensile strength, irrespective of the HD.

Young's modulus results from tensile test analysis for pure PLA and PLA/PVA blends are presented in Figure 5. As compared with pure PLA, it is observed a decrease in Young's modulus with increasing the content of PVA, particularly for blends with 20 wt.\% of PVA (HD: 98\%), indicating that presence of PVA affect the rigidity of PLA.

Influence of HD of PVA is clearer in Young's modulus values obtained by IET analysis presented in Table 4. For higher HD, increasing content of PVA from 10 to $20 \mathrm{wt} . \%$,

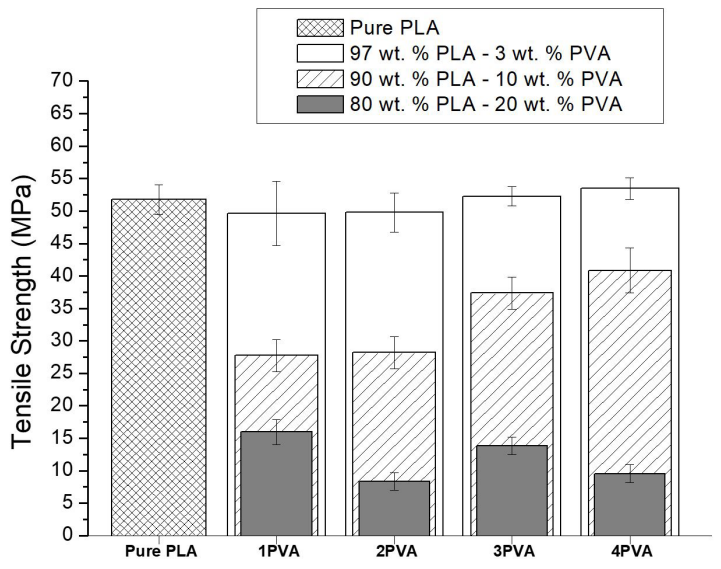

Figure 4. Tensile strength for pure PLA and PLA/PVA blends. decrease Young's modulus values, and for the same Mw, samples containing $20 \mathrm{wt}$ \% PVA with higher HD, present lower young's modulus. PVA present flexible characteristic, in this way is expected a decrease of rigidity in PLA/PVA blends, suggesting that acetate groups present in PVA with lower HD influence the mobility of polymeric chains in the blends. In this context, according to DSC results, the lowering of crystallinity of PLA in presence of PVA can lead a decrease in mechanical properties of PLA/PVA blends.

Results reported for Shuai et al., 2001 and H. Tsuji, $2001^{[12,14]}$, pointing out that the lowering of mechanical properties with increasing PVA content was attributed to the partial compatibility of the blends, due to the weak interfacial adhesion between the two phases in PLA/PVA blends. However, PVA with higher Mw conferring more resistance to PLA/PVA blends acts like a cross-linked component between molecules of PVA and PLA.

\subsection{SEM Analysis}

Figure 6 shows cross-section SEM images of selected PLA/PVA blends. In general, is observed a porous morphology for all blends, related to the partially compatible nature of PLA/PVA blends.

However, the content of PVA had a remarkable influence on blends morphology, as evidenced in the characteristics of the observed pores. In this context, blends with higher content of PVA have higher density of pores, indicating a greater phase separation, unlike blends containing less

Table 4. Young's modulus from IET for pure PLA and PLA/PVA blends.

\begin{tabular}{lccc}
\hline \multirow{2}{*}{ Sample code } & \multicolumn{3}{c}{ Young's Modulus (GPa) } \\
\cline { 2 - 4 } & $\mathbf{8 0 / 2 0}$ wt.\% & $\mathbf{9 0 / 1 0}$ wt.\% & $\mathbf{1 0 0}$ wt.\% \\
\hline Pure PLA & & & 4.7 \\
PLA/1PVA & 4.3 & 4.1 & \\
PLA/2PVA & 2.1 & 4.0 & \\
PLA/3PVA & 4.1 & 4.0 & \\
PLA/4PVA & 3.0 & 4.2 & \\
\hline
\end{tabular}

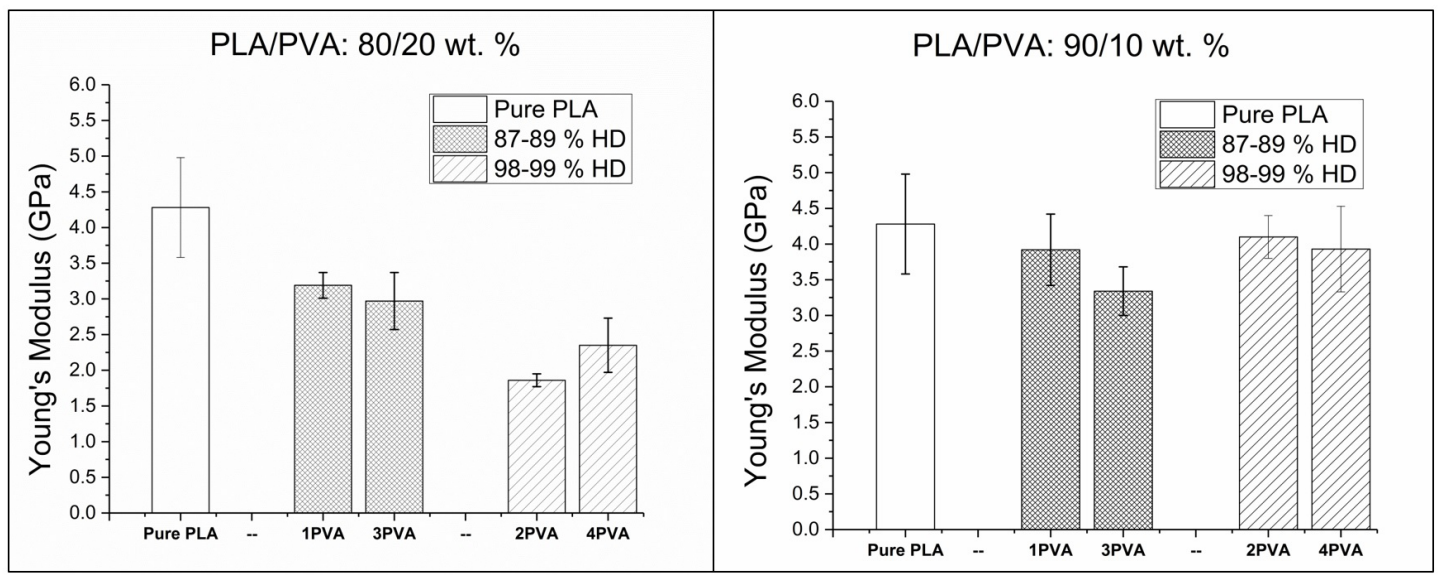

Figure 5. Young's modulus from tensile test for pure PLA and PLA/PVA blends. 

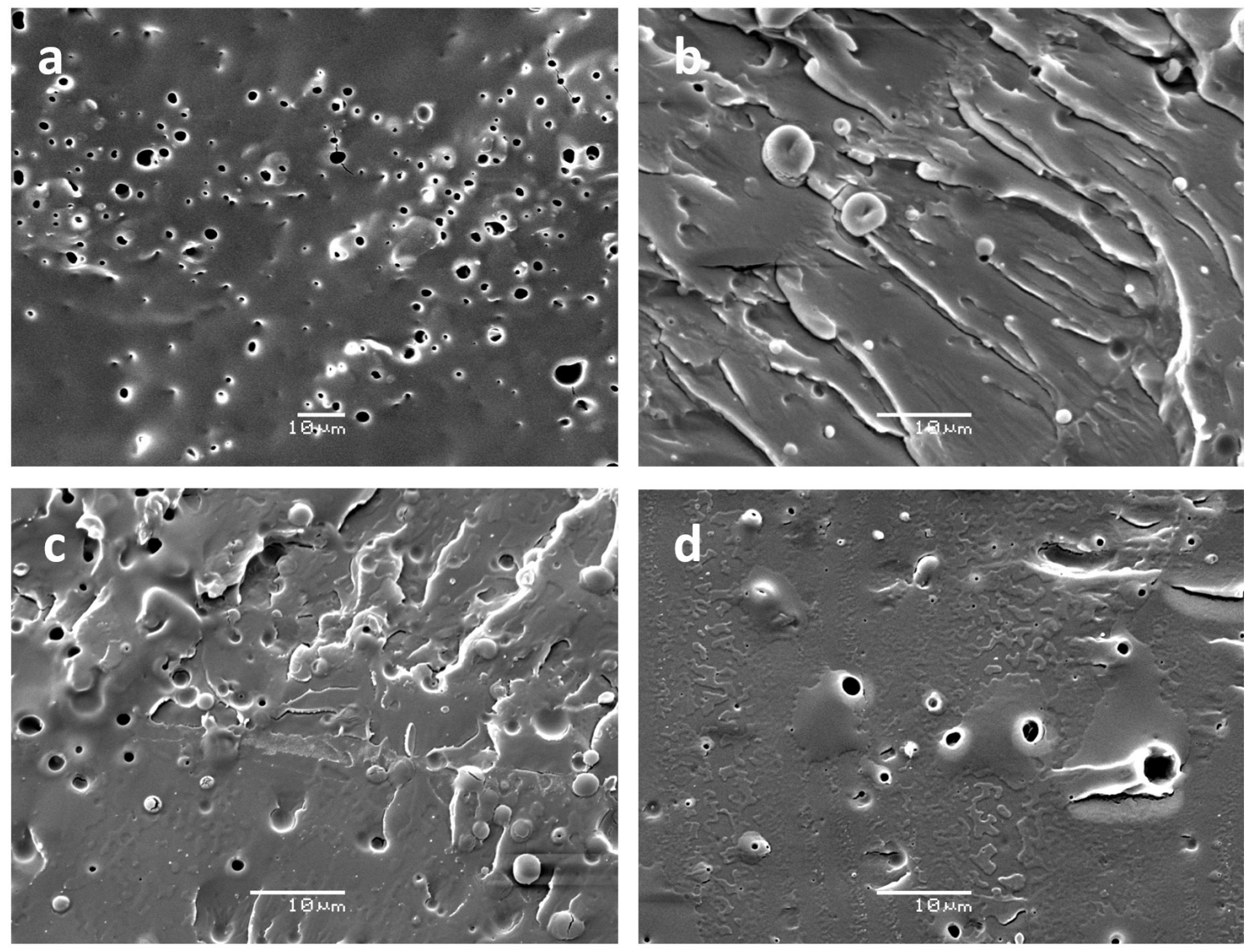

Figura 6. SEM images of selected PLA/PVA blends: (a) 3PVA 80/20; (b) 4PVA 80/20; (c) 3PVA 97/3; (d) 4PVA 97/3.

PVA (particularly with high Mw and independent of the HD), which have smaller pores, suggesting that the compatibility of PVA and PLA was improved on addition of low quantities of PVA with higher Mw.

In this context, Zhang et al., (2012) ${ }^{[34]}$ reported that increasing the PVA content (polymerization degree:1700, HD:88\%) from 10 to 80 wt. $\%$ in PLA/PVA blends produced a less smooth surface. This was attributed to an excessive PVA content that led to strong and extensive intermolecular hydrogen bonding, which in turn resulted in PLA aggregation. Other reports showed development of pores with an average size of $5 \mu \mathrm{m}$ for 50/50 PLA/PVA blends, suggesting the formation of two separate phases; a PLA-rich phase forming domains leading to porosity and a continuous PVA-rich phase ${ }^{[14]}$.

\section{Conclusions}

The partially compatible nature of PLA/PVA blends were evidenced from thermal and mechanical results. In this context, were observed one peak of Tg for PLA/PVA blends, intermediate between the Tg values of pure PLA and PVA, characteristic behavior of compatible blends. Additionally, for a higher content of PVA, decrease crystallinity of PLA, thus, PLA/PVA blends with $20 \mathrm{wt} . \%$ of PVA tend to reduce mechanical properties of PLA, particularly for those with $98 \%$ HD. However, the addition of low quantities of PVA (3 wt. \%) do not reduce the tensile strength in PLA/PVA blends, because of better compatibility between PLA and PVA. PVA's with higher $\mathrm{Mw}$ favors the entanglement of PVA and PLA improving the thermal stability of PLA/PVA blends. With increasing PVA content in the blends, the main degradation step is shifted significantly to lower temperatures, however PVA with HD of $87-89 \%$, present better thermal stability due to acetate groups conferring higher thermal decomposition temperatures to PVA, favoring the thermal stability of the PLA/PVA blends.

\section{Acknowledgements}

This work has been financed by projects of Comisión Nacional de Investigación Científica y Tecnológica CONICYT (Beca de Doctorado Nacional - Proyecto PAI 781411004), CONICYT-REGIONAL R08C1002 and Programa de Financiamiento Basal para Centros Científicos y Tecnológicos de Excelencia PFB-27. The authors thank to Carmen Pradenas for sample testing.

\section{References}

1. Ge, H., Yang, F., Hao, Y., Wu, G., Zhang, H., \& Dong, L. (2013). Thermal, mechanical and rheological properties of plasticized poly (L-lactic acid). Journal of Applied Polymer Science, 127(4), 2832-2839. http://dx.doi.org/10.1002/app.37620. 
2. European Bioplastic (2016). Bioplastics market data. Retrieved in 2017, April 28, from www.europeanbioplastics.org/market/

3. Auras, R., Harte, B., \& Selke, S. (2004). Effect of water on the oxygen barrier properties of poly (ethylene terephthalate) and polylactide films. Journal of Applied Polymer Science, 92(3), 1790-1803. http://dx.doi.org/10.1002/app.20148.

4. Auras, R., Harte, B., \& Selke, S. (2004). An overview of polylactides as packaging materials. Macromolecular Bioscience, 4(9), 835-864. PMid:15468294. http://dx.doi.org/10.1002/ mabi.200400043.

5. Auras, B. R. A., Singh, S. P., \& Singh, J. J. (2005). Evaluation of oriented poly(lactide) polymers vs. existing pet and oriented ps for fresh food service containers. Packaging Technology \& Science, 18(4), 207-216. http://dx.doi.org/10.1002/pts.692.

6. Suyatma, N. E., Copinet, A., Tighzert, L., \& Coma, V. (2004). Mechanical and barrier properties of biodegradable films made from chitosan and poly (lactic acid) blends. Journal of Polymers and the Environment, 12(1), 1-6. http://dx.doi. org/10.1023/B:JOOE.0000003121.12800.4e.

7. Rudnik, E., \& Briassoulis, D. (2010). Comparative biodegradation in soil behaviour of two biodegradable polymers based on renewable resources. Journal of Polymers and the Environment, 19(1), 18-39. http://dx.doi.org/10.1007/s10924-010-0243-7.

8. Kale, G., Kijchavengkul, T., Auras, R., Rubino, M., Selke, S., $\&$ Singh, S. P. (2007). Compostability of bioplastic packaging materials: an overview. Macromolecular Bioscience, 7(3), 255277. PMid:17370278. http://dx.doi.org/10.1002/mabi.200600168.

9. Li, H.-Z., Chen, S.-C., \& Wang, Y.-Z. (2014). Thermoplastic PVA/ PLA blends with improved processability and hydrophobicity. Industrial \& Engineering Chemistry Research, 53(44), 1735517361. http://dx.doi.org/10.1021/ie502531w.

10. Wang, H., Sheng, M., Zhai, L., \& Li, Y. (2008). Study on hydrophilicity and degradability of polyvinyl alcohol/polylactic acid blend film. Journal of Biomedical Engineering, 25(1), 139-142. PMid:18435276.

11. Yeh, J.-T., Yang, M.-G., Wu, C.-H., Wu, X., \& Wu, C.-S. (2008). Study on the crystallization kinetic and characterization of poly (lactic acid) and poly(vinyl alcohol) blends. Polymer-Plastics Technology and Engineering, 47(12), 1289-1296. http://dx.doi. org/10.1080/03602550802497958.

12. Shuai, X., He, Y., Asakawa, N., \& Inoue, Y. (2001). Miscibility and phase structure of binary blends of poly (1-lactide) and poly (vinyl alcohol). Journal of Applied Polymer Science, 81(3), 762-772. http://dx.doi.org/10.1002/app.1493.

13. Lipsa, R., Tudorachi, N., \& Vasile, C. (2008). Poly (vinyl alcohol)/poly (lactic acid) blends biodegradable films doped with colloidal silver. Revue Roumaine de Chimie, 53(5), 405-413. Retrieved in 2017, April 28, from https://www.researchgate. net/publication/237081349

14. Tsuji, H., \& Muramatsu, H. (2001). Blends of aliphatic polyesters IV. Morphology swelling behavior, and surface and bulk properties of blends from hydrophobic poly (L -lactide) and hydrophilic poly (vinyl alcohol), 1-4. Journal of Applied Polymer Science, 81(9), 2151-2160. http://dx.doi.org/10.1002/ app.1651.

15. An Tran, N. H., Brünig, H., Hinüber, C., \& Heinrich, G. (2014). Melt spinning of biodegradable nanofibrillary structures from poly (lactic acid) and poly (vinyl alcohol) blends. Macromolecular Materials and Engineering, 299(2), 219-227. http://dx.doi. org/10.1002/mame.201300125.

16. Jazrawi, B., Noroozi, N., Ansari, M., \& Hatzikiriakos, S. G. (2013). Processing aids for biodegradable polymers. Journal of Applied Polymer Science, 128(6), 3592-3600. http://dx.doi. org/10.1002/app.38562.

17. Pyda, M., Bopp, R. C., \& Wunderlich, B. (2004). Heat capacity of poly (lactic acid). The Journal of Chemical Thermodynamics, 36(9), 731-742. http://dx.doi.org/10.1016/j.jct.2004.05.003.

18. Lim, R.-T., Auras, R., \& Rubino, M. (2008). Processing technologies for poly (lactic acid). Progress in Polymer Science, 33(8), 820852. http://dx.doi.org/10.1016/j.progpolymsci.2008.05.004.

19. Leissa, A. W. (1973). The free vibration of rectangular plates. Journal of Sound and Vibration, 31(3), 257-293. http://dx.doi. org/10.1016/S0022-460X(73)80371-2.

20. Fukushima, K., Tabuani, D., \& Camino, G. (2009). Nanocomposites of PLA and PCL based on montmorrillonite and sepiolite. Materials Science and Engineering C, 29(4), 1433-1441. http:// dx.doi.org/10.1016/j.msec.2008.11.005.

21. Pluta, M. (2006). Melt compounding of polylactide/organoclay: structure and properties of nanocomposites. Journal of Polymer Science Part B Polymer Physics, 44(23), 3392-3405. http:// dx.doi.org/10.1002/polb.20957.

22. Zhang, L., Goh, S. H., \& Lee, S. Y. (1998). Miscibility and crystallization behavior of poly(L-lactide)/poly(p-vinylphenol) blends. Polymer, 39(20), 4841-4847. http://dx.doi.org/10.1016/ S0032-3861(97)10167-7.

23. Tsuji, H. (2005). Poly(lactide) stereocomplexes: formation, structure, properties, degradation, and applications. Macromolecular Bioscience, 5(7), 569-597. PMid:15997437. http://dx.doi.org/10.1002/mabi.200500062.

24. Nalbandi, A. (2001). Kinetics of thermal degradation of polylactic acid under $\mathrm{N}_{2}$ atmosphere. Iranian Polymer Journal, 10(6), 371-376. Retrieved in 2017, April 28, from http://en.journals. sid.ir/ViewPaper.aspx?ID=17392

25. Ding, J., Chen, S., Wang, X., \& Wang, Y. (2009). Synthesis and properties of thermoplastic poly (vinyl alcohol) -graft-lactic acid copolymers. Industrial \& Engineering Chemistry Research, 48(2), 788-793. http://dx.doi.org/10.1021/ie8013428.

26. Holland, B. J., \& Hay, J. N. (2001). The thermal degradation of poly (vinyl alcohol). Polymer, 42(16), 6775-6783. http:// dx.doi.org/10.1016/S0032-3861(01)00166-5.

27. Ballistreri, A., Foti, S., Montaudo, G., \& Scamporrino, E. (1980). Evolution of aromatic compounds in the thermal decomposition of vinyl polymers. Journal of Polymer Science: Polymer Chemistry Edition, 18, 1147-1153.

28. Maria, T. M. C., Carvalho, R. A., Sobral, P. J. A., Habitante, A. M. B. Q., \& Solorza-Feria, J. (2008). The effect of the degree of hydrolysis of the PVA and the plasticizer concentration on the color, opacity, and thermal and mechanical properties of films based on PVA and gelatin blends. Journal of Food Engineering, 87(2), 191-199. http://dx.doi.org/10.1016/j. jfoodeng.2007.11.026.

29. Peng, Z., \& Kong, L. X. (2007). A thermal degradation mechanism of polyvinyl alcohol/silica nanocomposites. Polymer Degradation \& Stability, 92(6), 1061-1071. http:// dx.doi.org/10.1016/j.polymdegradstab.2007.02.012.

30. Alexy, P., Bakos, D., Crkonova, G., Kolomaznik, K., \& Krsiak, M. (2001). Blends of Polyvinyl alcohol with collagen hydrolysate: thermal degradation and processing properties. Macromolecular Symposia, 170(1), 41-49. http://dx.doi.org/10.1002/15213900(200106)170:1<41::AID-MASY41>3.0.CO;2-B.

31. Assendert, H. E., \& Windle, A. H. (1998). Crystallinity in poly (vinyl alcohol). An X-ray diffraction study of atactic PVOH. Polymer, 39(18), 4295-4302. http://dx.doi.org/10.1016/S00323861(97)10296-8. 
32. Puiggali, J., Ikada, Y., Tsuji, H., Cartier, L., Okihara, T., \& Lotz, B. (2000). The frustrated structure of poly(L-lactide). Polymer, 41(25), 8921-8930. http://dx.doi.org/10.1016/S00323861(00)00235-4.

33. Tabatabaei, S. H., \& Ajji, A. (2011). Crystal structure and orientation of uniaxially and biaxially oriented PLA and PP nanoclay composite films. Journal of Applied Polymer Science, $124,4854-4863$.
34. Zhang, R., Xu, W., \& Jiang, F. (2012). Fabrication and characterization of dense chitosan/polyvinyl-alcohol/ polylactic-acid blend membranes. Fibers and Polymers, 13(5), 571-575. http://dx.doi.org/10.1007/s12221-012-0571-4.

Received: Apr. 28, 2017

Revised: June 14, 2017 Accepted: July 05, 2017 